\title{
EDITORIAL
}

\section{Does Europe need paediatric virologists?}

\author{
IOANNIS N. MAMMAS ${ }^{1}$, ANNE GREENOUGH ${ }^{2}$, MARIA THEODORIDOU $^{3}$ and DEMETRIOS A. SPANDIDOS ${ }^{1}$
}

${ }^{1}$ Department of Clinical Virology, School of Medicine, University of Crete, Heraklion 71003, Greece; ${ }^{2}$ Division of Asthma, Allergy and Lung Biology, King's College London, London SE5 9RS, UK; ${ }^{3}$ 1st Department of Paediatrics, 'Aghia Sophia'

Children's Hospital, Athens Medical School, National and Kapodistrian University of Athens, Athens 115 27, Greece

Received June 22, 2018; Accepted July 23, 2018

DOI: $10.3892 /$ etm.2018.6548

Paediatric virology is a rapidly increasing educational challenge, which combines neonatology and paediatrics with clinical virology. Over the past three decades, our knowledge of congenital, perinatal, neonatal and paediatric infections has excessively increased (1). Novel prevention strategies and therapeutic protocols have been evaluated for emerging viral diseases, while new vaccines and antiviral agents are currently under investigation. Paediatric health professionals are becoming increasingly involved in the specialised care of paediatric patients, who require enhanced medical management and innovative technological services. Moreover, recently newfound social issues have arisen, including the financial crisis and the unprecedented human migration occurring globally, and in the Mediterranean countries in particular. In light of these ongoing advancements and challenges, our proposal for paediatric virology subspecialty (2) has already attracted the critical interest of several worldwide experts in the scientific fields of neonatology, paediatrics, paediatric infectious diseases and virology (3-5).

In Europe, as it will be highlighted in the context of the '4th Workshop on Paediatric Virology' (6-9), paediatric virologists are definitely required and should exist in the tertiary centres of each country, having a strategically principal role, both clinical and academic, in the fight against viral infections occurring in neonates and children. In the UK, for example, with a population which grew to an estimated 65.1 million in 2015, paediatric virologists of the National Health System (NHS) should be located in UK reference centres, providing they have the capacity to provide comprehensive coverage for the UK between them. Their training should be advanced,

Correspondence to: Professor Demetrios A. Spandidos, Department of Clinical Virology, School of Medicine, University of Crete, Heraklion 71003, Greece

E-mail: spandidos@spandidos.gr

Key words: paediatrics, medical education, paediatric subspecialties, paediatric virology, Europe as they will be required to consult on complex cases with consultants in neonatology, paediatrics, paediatric infectious diseases and microbiology experts with experience in viral diseases (10). Current training pathways in paediatric virology include the subspecialty of paediatric infectious diseases, as well as specialised MScs, MRes, PhDs and Diplomas; to date, in Europe, no specialised educational programme on paediatric virology exists.

Paediatric subspecialty education involves the state-of-the-art training and practice on specific scientific fields of paediatrics requiring clinical expertising and academic excellence (11). Given the limited job opportunities of the subspecialists, it is important that there is a national scheme providing an approved route to subspecialist accreditation, which is matched to workforce needs and which provides equity of access to quality assured training (11-13). Despite the fact that the number of paediatric virologists in any one country is likely to be small, a separate paediatric subspecialty needs to be considered carefully by official institutions, such as the Royal College of Paediatrics and Child Health (RCPCH). This will lead to the creation of specialised programmes on paediatric virology in each country, which will be provided by both clinicians and basic scientists. This innovative approach will cover the increasing needs for specialised, neonatal and paediatric health care provided by paediatric health professionals trained specifically in emerged viral infections. It will also boost forward research in the field and promote the level of paediatric education and teaching in Europe (14). The subspecialty medical training scheme is not static, but improves with experience; paediatric virology can be an excellent candidate to prove it.

\section{References}

1. Greenough A, Osborne J and Sutherland S (eds): Congenital, perinatal, and neonatal infections. In: Reproductive Toxicology. Churchill Livingstone, New York, NY, p529, 1992.

2. Mammas IN, Greenough A, Theodoridou M and Spandidos DA: Paediatric Virology: A new paediatric subspecialty? A proposal at the Workshop on Paediatric Virology, Athens, October 10, 2015. Exp Ther Med 11: 3-5, 2016.

3. Mammas IN, Greenough A, Theodoridou M, Kramvis A, Christaki I, Koutsaftiki C, Koutsaki M, Portaliou DM, Kostagianni G, Panagopoulou P, et al: Current views and advances on Paediatric Virology: An update for paediatric trainees. Exp Ther Med 11: 6-14, 2016. 
4. Mammas IN, Theodoridou M, Kramvis A, Thiagarajan P, Gardner S, Papaioannou G, Melidou A, Koutsaki M, Kostagianni G, Achtsidis V, et al: Paediatric Virology: A rapidly increasing educational challenge. Exp Ther Med 13: 364-377, 2017.

5. Mammas IN and Spandidos DA: The subspecialty of Paediatric Virology: A 'mosaic tile' in future Paediatrics. Exp Ther Med 12: 539-540, 2016

6. Mammas IN and Spandidos DA: Evaluating the proposal of paediatric virology: An interview with Professor Tina Dalianis, Professor of Tumour Virology at Karolinska Institutet. Exp Ther Med (In press).

7. Mammas IN and Spandidos DA: Neonatology, paediatrics and paediatric virology on a British island: An interview with neonatologist Dr Prakash Thiagarajan (Isle of Man). Exp Ther Med (In press)

8. Mammas IN and Spandidos DA: Paediatric virology as a candidate of paediatric subspecialisation: An interview with Assistant Professor of Molecular Microbiology-Virology Angeliki Melidou. Exp Ther Med (In press).

9. Mammas IN and Spandidos DA. The philosophy of paediatric teaching: An interview with Dr Nikolaos Myriokefalitakis, former Clinical Director of the 'Penteli' Children's Hospital in Athens (Greece). Exp Ther Med (In press).
10. Mammas IN and Spandidos DA: The educational challenge of Paediatric Virology: An interview with Professor of Neonatology Anne Greenough. Exp Ther Med 14: 3332-3334, 2017.

11. RCPCH: Sub-specialties. Royal College of Paediatrics and Child Health, 2018. Available at: https://www.rcpch.ac.uk/education/ careers-paediatrics/sub-specialties.

12. Shortland D, Roland D, Lumsden DE, Ewing C, L'Esperance V, McColgan M, Winch R and Mahmood S: Career intentions and choices of paediatricians entering training in the UK. Arch Dis Child 100: 537-541, 2015.

13. Brown CC, Apps JR, Davies G, Ware N, Fisher J and Winyard PJ: Making your way as an academic paediatric trainee in the UK. Arch Dis Child Educ Pract Ed 99: 13-14, 2014.

14. Stewart D: Medical training in the UK. Arch Dis Child 88: $655-658,2003$

(i) $\Theta$ This work is licensed under a Creative Commons Attribution-NonCommercial-NoDerivatives 4.0 International (CC BY-NC-ND 4.0) License. 